\title{
The Century Club: A model for staff-supported medical education
}

\author{
CHRISTOPHER T. MEYER, DO
}

Osteopathic teaching hospitals are frequently criticized by house staff officers for not being sufficiently didactic or academically oriented. A model for providing academic training for students, interns, and residents as well as continuing medical education for attending staff physicians is described. This model may be administered by a department of medical education at community hospitals. Taxdeductible financial contributions from medical staff physicians and grants from pharmaceutical companies will be adequate to support this model. Benefits include enhancement of teaching rounds, increased medical staff support, improved compliance with CME requirements, and development of a useful recruitment tool.

During the past 10 years, we have seen dramatic changes in the way that osteopathic physicians choose internships and residency training programs. The allopathic profession has opened its doors, with the result that more DOs are training in allopathic internal medicine and family practice residency programs than in our own osteopathic residency programs. Even more bothersome has been the trend for DO graduates to move directly into allopathic

Dr Meyer is vice president of medical education, Flint Osteopathic Hospital, Flint, Mich.

Reprint requests to Christopher T. Meyer, DO, vice president of medical education, Flint Osteopathic Hospital, 3921 Beecher Rd, Flint, MI 48532-3699. institutions without even serving osteopathic rotating internships.

In recent surveys conducted by the Academy of Osteopathic Directors of Medical Education (AODME), DOs were shown to perceive a quality difference between osteopathic and allopathic residency programs. Often, osteopathic teaching hospitals are criticized by students, interns, and residents for not being sufficiently didactic or academically oriented. The implication is that allopathic university-based training programs, with their legions of "teaching faculty," are better suited to offer meaningful academic programs to trainees. The osteopathic hospitals are sometimes criticized by even their attending physicians for not offering suitable continuing medical education (CME) programs to the medical staff. The quality of these programs is of interest to most staff physicians, inasmuch as they are required to accumulate $50 \mathrm{CME}$ credits annually.

In this article, I outline a plan that can be adopted by most osteopathic teaching hospitals to "kill two birds with one stone": to provide excellent academic instruction to interns and residents, thereby improving the quality of their training programs and making them more competitive with allopathic programs, and at the same time, to offer attending physicians an easy, economical way of meeting the annual $\mathrm{CME}$ requirements.

\section{Background}

In conducting academic programs for students, interns, and residents, osteopathic teaching hos- 
pitals have always been at a disadvantage in comparison with allopathic institutions. It is not difficult to understand why! Most allopathic training programs are based at universities and thus benefit from a university structure, a large full-time faculty, and a legion of secretaries. University physicians are paid to take care of patients, to do research, and to teach medical students and residents. In the university hospital, a premium is placed on research and teaching, which are considered just as important as seeing patients. Often the university-based physician is more academically oriented and has spent considerable time developing lectures and teaching techniques. At the university, with a full-time faculty paid to implement the training program, lectures and conferences are scheduled on a regular basis, they are of an acceptable quality, and only infrequently are they canceled.

Osteopathic teaching hospitals, in contrast, are not always affiliated with a university. Most of them are located in smaller communities. More important, their teaching faculties are completely private, and few, if any, physicians are paid to do research or to teach students and residents. The hospitals are staffed with directors of medical education, who, more often than not, serve part-time and whose departments are usually understaffed. The training programs are conducted by teaching physicians who are clinically oriented private practitioners. Thus, some of them may be less academically oriented than their university brethren; those who like to teach, give lectures, and conduct academic programs may have little time to do so because of their practice responsibilities. As a result, when they are required to lecture, these physicians may be unprepared or, worse yet, forced to cancel because of a busy day.

As a result of these trends, osteopathic hospitals acquire a reputation for having unreliable academic programs. On the other hand, the strength of osteopathic training programs lies in the in-depth, one-on-one exposure the students have to attending physi-cians with whom they spend considerable time. Allopathic universities may be known for their reliable educational programs, but the real trade- off is that their students do not spend nearly as much time with attending physicians and may do rounds with them only 3 days a week for an hour and a half each day. In osteopathic hospitals, the "apprenticeship" method of training works well; and if we could find a way to improve our academic programs, then the overall quality of osteopathic training programs would be enhanced, and allopathic programs might appear less attractive to our DO students and residents.

\section{Medical staff support-the first step}

At Flint Osteopathic Hospital (FOH) (Flint, Mich), more than 200 lectures were scheduled in the 1978-1979 academic year to provide training for house staff and CME credit for medical staff physicians. This schedule was dependent on our own staff physicians, who were private practitioners. With a cancellation rate of more than $60 \%$, only about 87 lectures were actually given; the scheduled speakers found themselves unprepared to lecture, or they had become caught up in one crisis after another that precluded their involvement in academic conferences. Searching for a way to solve this difficult problem, the Department of Medical Education seized on the idea of persuading the FOH medical staff to fund academic programs.

The idea was a simple one: If we could not have a full-time faculty of our own, then we would rent one! If we did not have full-time, academically oriented teachers, then we would import such "teachers on wheels" from places that did. For example, southeastern Michigan had a wealth of osteopathic and allopathic teaching talent. The area boasted four medical schools and more than a dozen major teaching hospitals. Each had its own faculty, complete with specialists, subspecialists, researchers, and teachers, all with more than a passing interest in academics. Since Flint was no more than 90 minutes away from any of those institutions, we believed that if we could find an appropriate source of revenue, we could enlist faculty from other institutions to provide educational programs at our hospital.

Although the FOH Department of Medical Education had an annual budget of close to 
$\$ 2$ million, most of the money was eaten up in salaries and benefits for interns and residents. Very little of it was left over for academic programs. Thus, in 1982, in order to find money to improve our academic schedules for training, the medical staff formed the Century Club. The club was developed as a subsidiary of the hospital, complete with its own bylaws, specifying that contributions could be used only for academic programs. The hospital agreed to provide accounting and checking services.

By attending staff and department meetings, we convinced our physicians that if they were willing to support medical education with individual tax-deductible contributions of $\$ 200$ a year, then the Department of Medical Education would be able to provide quality educational programs. Confident that we could recruit speakers from around the state to conduct more than enough monthly seminars to enhance the quality of our training programs, we promised to give at least ten seminars in 1982. Each seminar would provide 6.5 CME Category 1-A credits. Thus the total credits would more than satisfy the annual requirements for licensure of the staff physicians. By holding the seminars on site, we would be guaranteed a strong attendance by our house staff officers, and our staff physicians would have easy access to lectures that interested them.

Even the first year, the Century Club was quite successful; we were able to persuade 105 staff physicians to join, which gave us an operating budget of $\$ 21,000$ for academic programs (Fig 1). With local speakers from Michigan medical schools, osteopathic hospitals, and teaching hospitals like Henry Ford and William Beaumont, we were easily able to conduct ten seminars, which were well received by our medical staff physicians and house staff officers. These seminars and the daily lectures that followed all came to be known as the Congdon Lecture Series.

In 1983 , knowing that we would receive at least $\$ 20,000$ in support from our own medical staff, we approached pharmaceutical companies throughout the country. We developed a letter in which we explained our goals, outlined the traditional problems that osteopathic hospitals had in providing graduate medical education, and requested support for our academic programs and sent a copy to each pharmaceutical company. The response was overwhelming. Eventually we received grants on a monthly basis or promises to provide speakers as well as travel support and accommodations. With assistance from the pharmaceutical companies, our budget increased, and we recognized that we would be able to increase the quality of the programs.

We next developed an individualized form letter in which we explained the Century Club and our academic goals at $\mathrm{FOH}$ and sent copies to prominent allopathic and osteopathic speakers throughout the United States. Again, the response was overwhelming. Before we knew it, we had the most prominent medical speakers from around the country coming to our hospital to speak in our auditorium to our house and medical staffs. We increased the number of yearly seminars from 10 to 12 and held one each month.

The Century Club is now in its ninth year. It has a total membership of more than 295, with more non-FOH osteopathic members than FOH members (136) (Fig 2), and a total budget of more than $\$ 60,000$. We have never missed a month of sponsoring seminars. More than 80 different medical seminars have been held, each covering a different subject. A prominent faculty, including both MD section heads and osteopathic speakers, has been recruited from around the state or country. Whenever possible, we have invited our medical staff members to become involved in the programs. For example, when a cardiology seminar is scheduled, the speakers arrive the evening before, and our cardiologists host a dinner for them. One or two of the residents are invited to attend, and thus our local cardiologists rub arms and exchange opinions with cardiologists from Harvard or Northwestern as well as from the Texas College of Osteopathic Medicine or the Philadelphia College of Osteopathic Medicine. Our cardiologists participate in the seminar itself by introducing the speakers, serving as moderators, and conducting the panel discussions. Each month, then, we have a different seminar: One month it will be general surgery; 


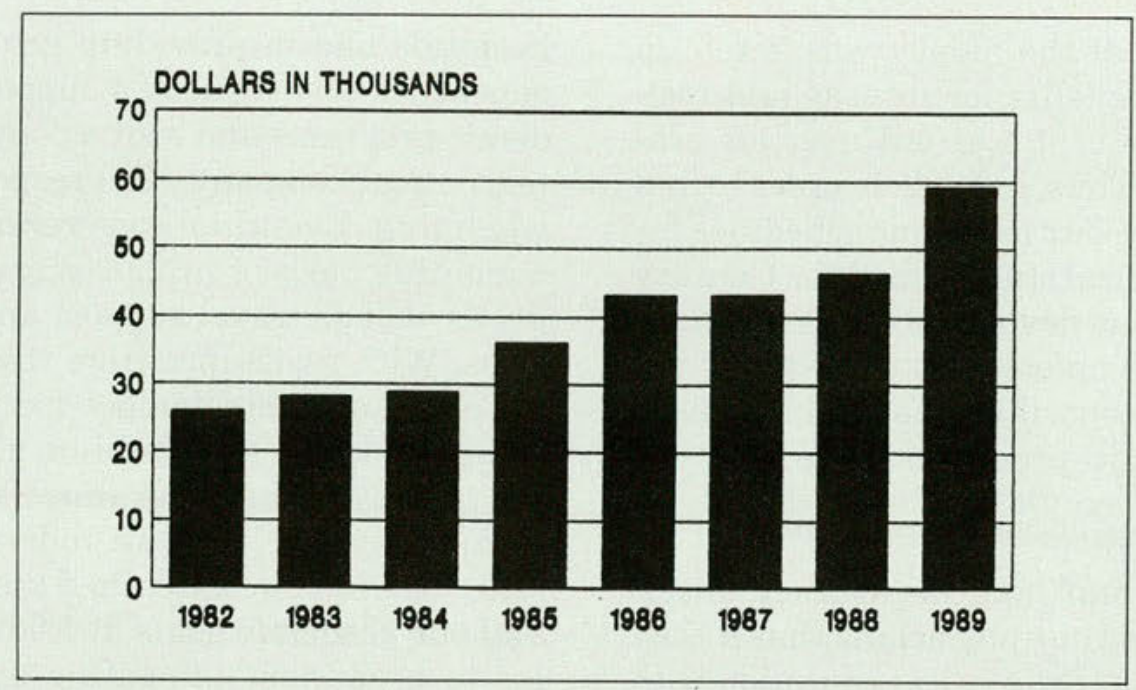

Figure 1. Flint (Mich) Osteopathic Hospital ( $\mathrm{FOH}$ ) Century Club revenue.

the next, urology or orthopedics and sports medicine; and so forth.

By the fourth year, the membership and budget of the Century Club had grown so large that we were no longer able to spend all the money on the monthly seminars and turned our attention toward daily lectures (Fig 2). Again, the idea was a simple one: If our own staff physicians were too busy to lecture, or did not like to lecture, then perhaps we could recruit physicians from around southeastern Michigan to participate in what we would call our Daily Lecture Series. Such a series would improve the quality of the educational program, reduce cancellations, and leave our own attending physicians free for what they were most interested in-teaching on the floors.

We developed a catalog with the names of most of the MD and DO physicians in southeast Michigan who were on the lecture circuit. We again drafted a letter in which we explained our program and our purposes and sent a copy to each physician listed, asking him or her to speak on a topic of personal choice for a stipend of $\$ 150$. (Having restricted ourselves to local speakers, for whom Flint would be within easy distance, we thought that $\$ 150$ might be an appropriate stipend to lure lecturers to our auditorium.)

In that fourth year, we had enough money not only to conduct a seminar each month but also to recruit approximately 15 guest speakers each month. These speakers, both MDs and DOs, were physicians who liked to lecture, who were prepared to lecture, and who showed up on time. Word of our academic programs spread through the student, intern, and resident ranks. We began to see more and more students showing up for intern interviews who had heard about the Century Club and the Congdon Lecture Series and daily lecture program. Today we have more than 200 guest speakers each year.

Meanwhile our medical staff physicians were enthralled with the program. For a yearly donation of $\$ 200$, tax deductible, they received more than $72 \mathrm{CME}$ Category I-A credits for the seminars alone. That turned out to be about $\$ 2.78$ per credit. Each year since 1982 , the number of our medical staff contributors has increased, and in 1989, only one $\mathrm{FOH}$ staff member failed to join the Century Club. Attendance by staff physicians and other local DOs has steadily increased through the 9 years of the program (Fig 3). Furthermore, our staff physicians began talking about the program to physicians in the area who were not on the FOH medical staff. In 1984, we began advertising the program to all osteopathic physicians in Genesee, Lapeer, and Shiawasse coun- 


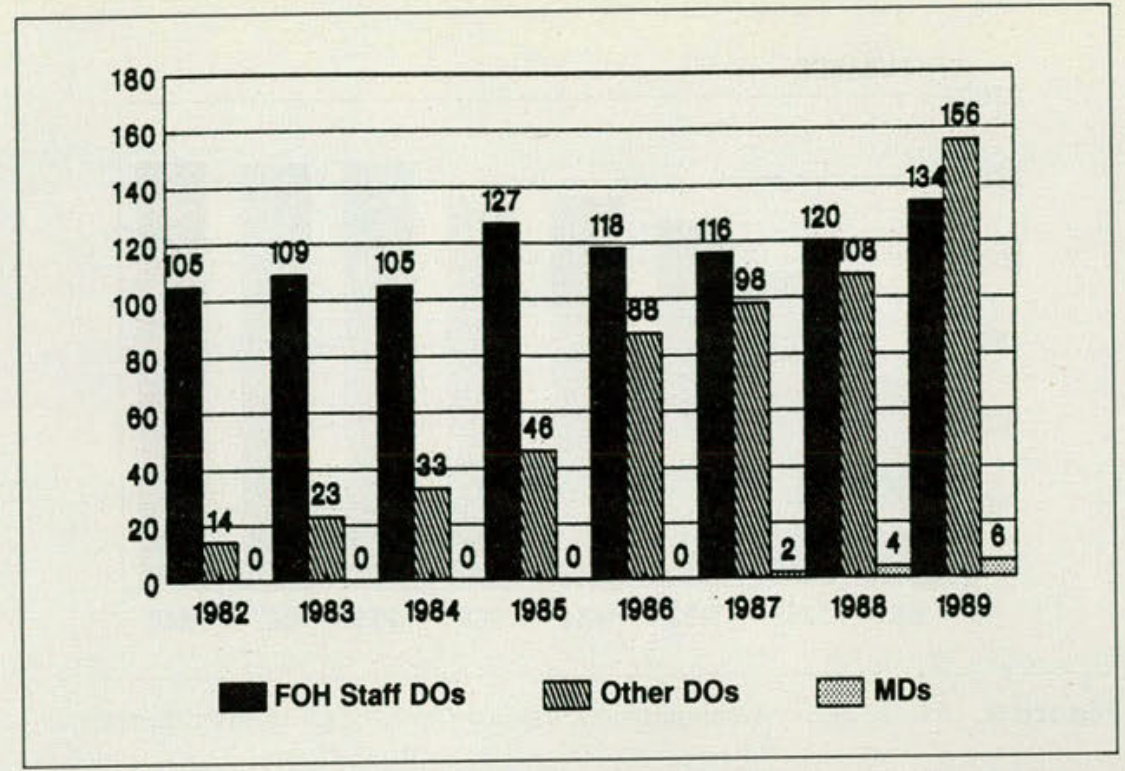

Figure 2. Flint (Mich) Osteopathic Hospital (FOH) Century Club membership.

ties as well as to all osteopathic physicians in northern Michigan, who frequently did not have access to good osteopathic CME programs. The response was favorable, and we picked up 46 physicians who were not on the FOH medical staff as new members. Today our membership includes more physicians from outside our hospital than those on our own staff (Fig 2).

In 1985, our budget increased even more, and we began to fine tune the program. For our seminars, we searched for more and more excellent speakers with bigger names who would be better received by members of our medical staff and physicians in training. We tried to strengthen our daily lecture series by having appropriate contributions from both the medical and the surgical specialties. Now only those FOH staff members who like to lecture are encouraged to participate in the program, and about $80 \%$ of all the daily lectures are given by guest speakers. The annual cancellation rate is less than $2 \%$.

Encouraged by our success at recruiting nonFOH staff members into the Century Club, we developed an individualized form letter to send to osteopathic physicians north of Detroit, in which we again explained the entire Century Club program and $\mathrm{FOH}$ educational goals. We have continued to send out copies each year, and the response has been rewarding.

\section{Benefits}

By means of the Century Club and the Congdon Seminars and Daily Lecture Series, we have surpassed our wildest expectations in achieving our initial goals. Through the contributions of our medical staff members and other osteopathic physicians in the area who are interested in continuing medical education, we have developed a sizable budget that is independently controlled by the Department of Medical Education. These revenues are used to support our educational programs and to enhance the academic standing of our hospital in the eyes of osteopathic house staff officers. A number of benefits have accrued through the development of the Century Club.

\section{Enhanced academic credibility}

The development of the Century Club has facilitated the restructuring of our academic programs and enhanced the ability of the hospital to train students, interns, and residents. Before founding the Century Club, we, like all osteopathic training hospitals, were dependent on our own medical staff physicians for providing academic instruction to our house staff officers. Unfortunately, our physicians had primary obligations to patients, spouses, partners, and children and then to students, interns, and residents. Frequently, they had to cancel their 


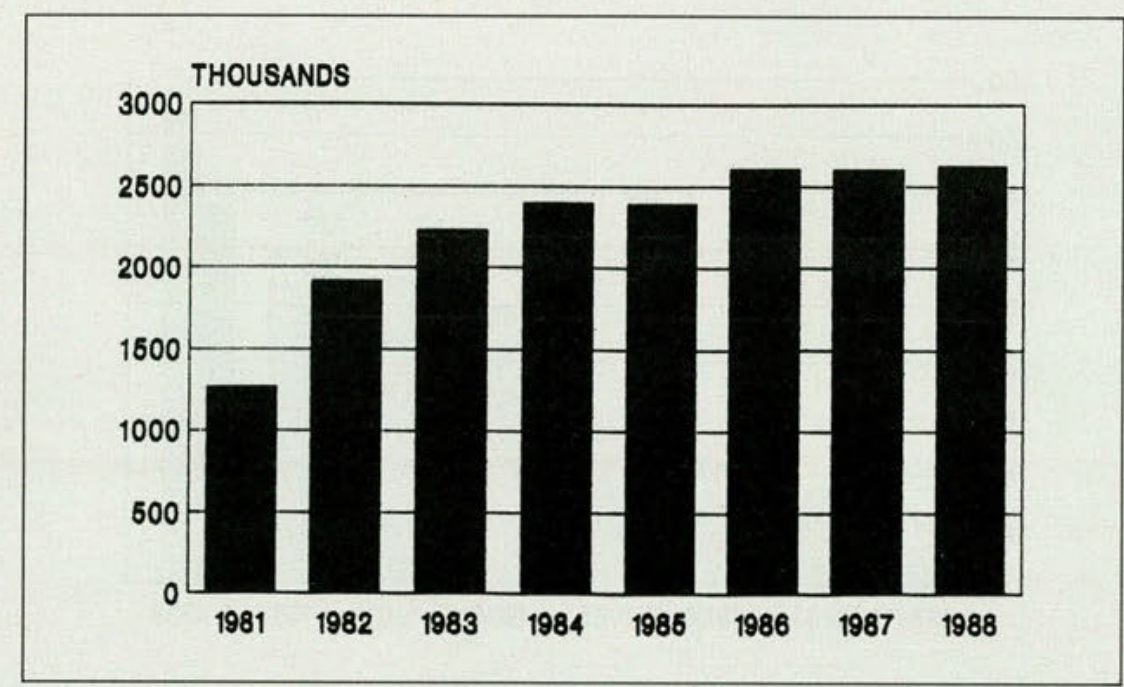

Figure 3. Flint (Mich) Osteopathic Hospital Century Club attendance.

lectures because of conflicting responsibilities. Then, too, the ability to lecture or to present an educational program is not a talent that is equally shared among physicians. With the monies provided by the Century Club, the Department of Medical Education has been able to recruit an academic faculty from throughout the state to rotate.into Flint by automobile and provide meaningful academic programs on a continuing basis. Our guest speakers want to lecture, they are prepared to lecture, and rarely if ever do they cancel because of conflicting responsibilities. Our Congdon Seminars and Daily Lecture Series have become known throughout the profession, and they attract a steady stream of osteopathic students who are interested in training at our hospital. These programs have helped create a "university atmosphere" at our community hospital.

\section{Enhancement of teaching rounds}

Since they are no longer responsible for auditorium lectures, our attending physicians are free to concentrate on teaching rounds and morning report programs. Many of them feel more comfortable with this format than they do with presenting formal lectures to large groups. Members of our medical staff who have a special talent for lecturing are still encouraged to participate, and because of their special interest, they rarely cancel out. As a result of the Century Club programs, the qual- ity of our "apprenticeship" type of training on the hospital floors has generally improved at FOH.

\section{Increased medical staff support}

Over the years, the development of the Century Club has involved our entire medical staff. All of our physicians support it and are aware of its activities. It is their financial contributions that bring speakers to the auditorium for our daily lectures and monthly seminars. With their dollars footing the bill, our attending physicians are more interested in seeing that our house staff officers attend the programs. They take a dim view of cutting academic programs and demand that the officers show up at the designated times. As a result, with our medical staff standing firmly behind our scheduled academic programs, participation by the house staff is increased.

\section{Improved compliance with CME requirements}

The development of the Century Club has eliminated any CME problems that our staff physicians may have had in the past. By joining the Century Club for $\$ 200$, the physicians are eligible to attend all the seminars as well as the daily lectures for CME credit. It is virtually impossible not to acquire more than 50 CME Category 1-A credits each year. The monthly seminars alone provide more than 72 such credits, and there are more than 200 daily 
guest lectures. Our physicians like the program because to acquire their credit, they are no longer obliged to scramble around looking for seminars. Furthermore, should they choose to attend out-of-state seminars, they can do so in a more leisurely fashion, which, of course, appeals to some physicians.

\section{A useful recruitment tool}

The Century Club has turned out to be a very useful recruitment tool. Over the years, we have kept meticulous records of the numbers and types of speakers. More than 600 visiting professors have participated in our monthly seminars; many of these have been preeminent in their fields and possessed national reputations.

Osteopathic physicians looking for training programs are impressed with the track record of the Century Club. Its guaranteed lectures and seminars, they feel, offer built-in structure and organization. These features have improved recruitment for our internship and particularly for our family practice and internal medicine residency programs. All of our residency programs are supported, however, since we frequently have visiting professors in ophthalmology, orthopedics, otorhinolaryngology, radiology, urology, and other specialty areas.

\section{Future directions}

In 1987, the Century Club programs were inspected by the Michigan State Medical Society and became the first osteopathic programs in the state to receive accreditation to provide CME credits to allopathic physicians. In 1988, we also received accreditation from the American Academy of Family Physicians, which is active in sponsoring educational programs for allopathic physicians. With both DO and MD speakers participating in our programs, we hope to attract more allopathic physicians from the area to our seminar and lectures in the future (Fig 2).

During the past 2 years, we have developed a continuing medical education committee, with broad representation from the medical staff, to plan our seminars and educational programs and to decide how excess revenues can be used to improve medical education at $\mathrm{FOH}$. Today, the money generated by Century Club membership exceeds our needs for lectures and guest speakers.

Almost any hospital of more than 100 beds can develop a service club like the FOH Century Club to conduct medical education programs. Medical staff physicians and pharmaceutical representatives are likely to respond positively to a well-planned campaign to educate them about the benefits of such a program. A well-thought-out form letter can be used to attract sponsorship and to recruit guest speakers and participants. Accounting and bookkeeping services can be provided by the hospital, and the entire program of seminars and lectures can be coordinated and scheduled by one good secretary. After the first year of successful operation, planning will become much easier. These initial efforts will be more than repaid by the many benefits that will accrue to the hospital from the development of a staff-supported service club. 